\title{
Sintetik Seismik Lingkungan Vulkanik
}

\author{
Muhammad Ghazalli, Amien Widodo, Firman Syaifuddin \\ Teknik Geofisika, Fakultas Teknik Sipil dan Perencanaan, Institut Teknologi Sepuluh Nopember (ITS) \\ Jl. Arief Rahman Hakim, Surabaya 60111 Indonesia \\ e-mail: amien@ce.its.ac.id; firman@geofisika.its.ac.id
}

\begin{abstract}
Abstrak - Eksplorasi hidrokarbon saat ini mengharuskan geosaintis untuk mencari area baru yang sebelumnya dianggap tidak menghasilkan hidrokarbon. Dengan ditemukannya rembesan minyak pada daerah vulkanik mengindikasikan adanya petroleum play aktif yang memiliki cadangan hidrokarbon. Ketidakmampuan gelombang seismik untuk menggambarkan bawah permukaan pada daerah vulkanik menjadikan dibutuhkannya pemodelan seismik. Pemodelan seismik akan memodelkan atau merekonstruksikan penjalaran gelombang seismik pada model geologi yang telah ditentukan, pada kasus ini model geologi yang digunakan adalah model geologi pada lingkungan vulkanik. Penelitian ini menggunakan 2 model, yang pertama adalah model "Kue Lapis" dan yang kedua adalah model "S erayu" yang merupakan model kompleks dari cekungan North Serayu di Jawa tengah. Kedua model tersebut memiliki lapisan basalt dengan tebal $200 \mathrm{~m}$ yang menutupi lapisan bawahnya yang menjadi target karena menyimpan cadangan hidrokarbon. Dari hasil pemodelan dapat dilihat fenomena gelombang ketika merambat melalui lingkungan vulkanik.
\end{abstract}

Kata Kunci- Lingkungan Vulkanik, Pemodelan Seismik, Pemodelan Ke depan, Cekungan Serayu.

\section{PENDAHULUAN}

$\mathrm{D}$ ENGAN semakin menipisnya cadangan hidrokarbon pada petroleum system yang konvensional memunculkan ide-ide baru dengan adanya cadangan migas pada daerah yang dianggap tidak dapat memproduksi migas, yaitu area lingkungan batuan vulkanik. Di pulau Jawa sendiri penemuan rembesan minyak dan gas paling banyak muncul di area vulkanik. Saking banyaknya rembesan minyak di area vulkanik sampai pernah memunculkan teori bahwa minyak dan gas itu memiliki asal magmatik (salah satu teori anorganik asal minyak yang pernah muncul pada zaman Hindia Belanda di Indonesia). Seiring berkembangnya pengetahuan lalu diketahui bahwa asal hidrokarbon adalah organik, yaitu dari zat renik organik (bakteri, plankton, ganggang) atau tumbuhan-tumbuhan di darat yang sebagian massanya menjadi komponen di batuan penggenerasi hidrokarbon (source rock). Batuan vulkanik ini menekan dan menenggelamkan batuan induk ke kedalaman yang menyebabkan zat organik di dalam batuan induk menjadi matang dan berubah menjadi minyak dan gas, lalu sebagian migas ini naik ke permukaan melalui celahcelah atau patahan-patahan dan menjadi rembesan minyak/gas di permukaan [1].

Tantangannya sekarang adalah teknologi pengambilan data (akuisisi) dan pengolahan data seismik sampai saat ini hampir tak mampu menembus lapisan tebal vulkanik untuk mengungkap konfigurasi lapisan batuan di bawah vulkanik (sub-vulcanic) dengan maksimal. Oleh karena itu dibutuhkan pemodelan data seismik untuk mengetahui dan memahami bagaimana respon gelombang seismik ketika menjalar melalui model geologi yang kompleks, dalam hal ini pada lingkungan batuan vulkanik

\section{TINJAUAN PUST AKA}

\section{A. Pemodelan Ke depan}

Pemodelan ke depan yang digunakan dalam penelitian ini adalah pemodelan gelombang akustik dalam medium isotropik. Untuk pemodelan akustik, properti medium dijelaskan sebagai sebaran ruang dengan parameter perambatan gelombang dari gelombang yaitu $\mathrm{v}=(\mathrm{x} 1, \mathrm{x} 3)$ dan densitas $\rho(\mathrm{x} 1, \mathrm{x} 3)$. Persamaan gelombang akustik dijelaskan sebagai medan vektor dari pemindahan kecepatan u dan medan skalar dari tekanan $\mathrm{p}$, keduanya menghasilkan persamaan sebagai berikut [2].

$\frac{\partial u_{1}}{\partial t}=\frac{1}{\rho} \frac{\partial p}{\partial x_{1}}$

$\frac{\partial u_{3}}{\partial t}=\frac{1}{\rho} \frac{\partial p}{\partial x_{1}}$

$\frac{\partial p}{\partial t}=\rho v^{2}\left(\frac{\partial u_{1}}{\partial x_{1}}+\frac{\partial u_{3}}{\partial x_{3}}\right)$

selanjutnya, turunkan persamaan 1 dengan $\mathrm{x}_{1}$, persamaan kedua dengan $\mathrm{x}_{3}$, dan persamaan ketiga dengan $\mathrm{t}$, maka didapatkan.

$\frac{\partial u_{1}}{\partial t \partial x_{1}}=\frac{\partial \frac{1}{\rho}}{\partial x_{1}} \frac{\partial p}{\partial x_{1}}+\frac{1}{\rho} \frac{\partial^{2} p}{\partial x_{1}^{2}}$

$\frac{\partial^{2} u_{3}}{\partial t \partial x_{3}}=\frac{\partial \frac{1}{\rho}}{\partial x_{3}} \frac{\partial p}{\partial x_{3}}+\frac{1}{\rho} \frac{\partial^{2} p}{\partial x_{3}^{2}}$

$\frac{\partial^{2} p}{\partial t^{2}}=p v^{2}\left(\frac{\partial^{2} u_{1}}{\partial t \partial x_{1}}+\frac{\partial^{2} u_{3}}{\partial t \partial x_{3}}\right)$

dengan mensubtitusikan persamaan 4 dan 5 ke persamaan 6 , maka didapatkan persamaan akustik dengan notasi tekanan.

$\frac{\partial^{2} p}{\partial t^{2}}=p v^{2}\left[\left(\frac{\partial \frac{1}{\rho}}{\partial x_{1}} \frac{\partial p}{\partial x_{1}}+\frac{1}{\rho} \frac{\partial^{2} p}{\partial x_{1}{ }^{2}}\right)+\left(\frac{\partial \frac{1}{\rho}}{\partial x_{3}} \frac{\partial p}{\partial x_{3}}+\frac{1}{\rho} \frac{\partial^{2} p}{\partial x_{3}{ }^{2}}\right)\right]$

persamaan 7 dapat disederhanakan menjadi,

$\frac{\partial^{2} p}{\partial t^{2}}=v^{2}\left(\frac{\partial^{2} p}{\partial x_{1}}+\frac{\partial^{2} p}{\partial x_{3}}\right)+p v^{2}\left(\frac{\partial \frac{1}{\rho}}{\partial x_{1}} \frac{\partial p}{\partial x_{1}}+\frac{\partial \frac{1}{\rho}}{\partial x_{3}} \frac{\partial p}{\partial x_{3}}\right)$

dapat dilihat pada persamaan 7 , terdapat persamaan yang menurunkan dengan densitas. Jika nilai tersebut mendekati 0 maka pada kasus ini akustik dan nilai skalar identik dengan tekanan. Perambatan gelombang bergantung kepada properti medium (tidak berubah seiring waktu - statik). Berikut beberapa properti yang mempengaruhi perambatan gelombang seis mik:

a. Kecepatan Primer (Vp) dan kecepatan sekunder (Vs), densitas $(\rho)$.

b. Properti tambahan seperti anisotropy (Parameter Thompson, atenuasi, dan absorpsi). 


\section{METODOLOGI PENELITIAN}

Data yang digunakan dalam tugas akhir ini adalah data sintetik dengan menggunakan model geologi sederhana dan model geologi skema pada lingkungan batuan vulkanik. Tahap pertama adalah membuat model geologi yang selanjutnya akan dilakukan akuisisi seis mik secara forward modelling, sehingga didapatkan data sintetik. Model geologi yang digunakan diusahakan mendekati model geologi lapangan sehingga diperlukan referensi lingkungan pengendapan di daerah batuan vulkanik (Facies Vulkanik) sebagai wawasan pembuatan model geologi (jenis batuan, struktur geologi dan morfologi) lalu dibutuhkan studi literatur untuk mengaitkan kondisi geologi yang diinginkan dengan propertifis is batuan seperti Kecepatan $\mathrm{P}$ dan densitas.

Setelah didapatkan model geologi lingkungan vulkanik yang diinginkan selanjutnya diberikan parameter akuisisi seperti jumlah channel, jumlah titik penembakan, near offset, far offset, record length, sampling time, dan frekuensi yang diberikan. Parameter akuisisi ini digunakan untuk tahapan selanjutnya yaitu forward modelling yang akan menghasilkan sintetik seis mogram.

\section{HASIL DAN ANALISA}

\section{A. Model Geologi Sederhana}

Model geologi sederhana merupakan model yang digunakan untuk melihat sifat perambatan gelombang seismik. Model yang digunakan adalah model lapisan tanpa struktur dengan memasukkan lapisan batuan basalt untuk melihat perambatan gelombang pada lapisan tersebut.

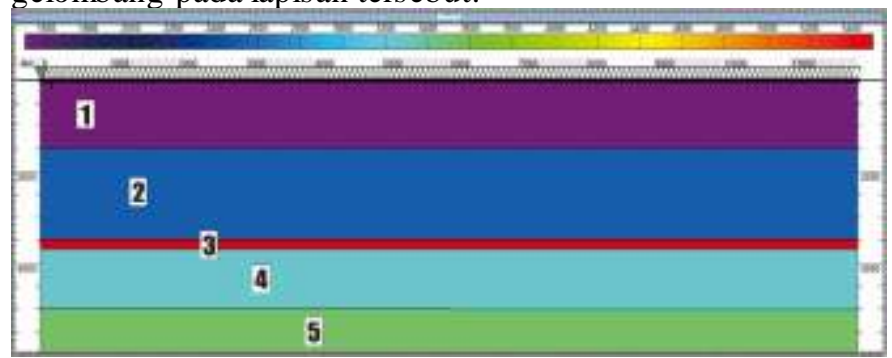

Gambar 1. Model Geologi “Kue Lapis” tanpa struktur dengan dimensi panjang $12 \mathrm{~km}$ dan kedalaman maksimum $6 \mathrm{~km}$.

Tabel 1. Parameter fisis model kue lapis.

\begin{tabular}{clcll}
\hline \hline $\begin{array}{c}\text { Lapisan } \\
\text { ke }\end{array}$ & $\begin{array}{c}\text { Tipe } \\
\text { Lapisan }\end{array}$ & $\begin{array}{c}\text { VP } \\
(\mathrm{m} / \mathrm{s})\end{array}$ & $\begin{array}{c}\text { Densitas } \\
\left(\mathrm{kg} / \mathrm{m}^{3}\right)\end{array}$ & $\begin{array}{c}\text { Ketebalan } \\
(\mathrm{m})\end{array}$ \\
\hline 1 & Sandstone & 1500 & 1970 & 1500 \\
2 & Sandstone & 2500 & 2200 & 2000 \\
3 & Basalt & 5500 & 2575 & 200 \\
4 & Sandstone & 3250 & 2237 & 1400 \\
5 & Sandstone & 3500 & 2275 & 1000 \\
\hline \hline
\end{tabular}

\section{B. Desain Akuisisi Model Kue Lapis}

Beberapa hal yang harus diperhatikan dalam menentukan desain akuisisi adalah ketebalan lapisan dan kedalaman lapisan target. Digunakan frekuensi sebesar $5 \mathrm{~Hz}$ dikarenakan hasil test parameter "Test Run". Penentuan far offset ditentukan kurang lebih 2 kali kedalaman, dikarenakan target memiliki kedalaman $6 \mathrm{Km}$ maka far offset yang digunakan sejauh $12 \mathrm{Km}$. Penentuan shot dan receiverinterval dihasilkan daripenggunaan grid yang digunakan, dikhawatirkan kualitas data akan menjadi kurang baik ketika interval geophone tidak mengikuti 2 kali lebar grid.

Tabel 2. Parameter akuisisi model kue lapis.

\begin{tabular}{ll}
\hline \hline Grid 20 meter & Frekuensi $5 \mathrm{~Hz}$ Wavelet Ricker \\
Shot Interval $80 \mathrm{~m}$ & Total Shot 150 \\
Receiver Interval $40 \mathrm{~m}$ & Total Receiver 301 \\
Record Length 7 sekon & Sampling Interval 2ms \\
\hline \hline
\end{tabular}

\section{Seismic Gather Model Kue Lapis}

Model geologi yang telah memiliki parameter fisis kemudian dilakukan forward modelling untuk melihat respon seismik nya. Dikarenakan model yang digunakan tanpa struktur, maka respon seismik nya memiliki penurunan waktu atau efek hiperbolik yang bagus. Respon yang tebal mengindikasikan terjadinya refleksi dengan lapisan. Ada beberapa respon tipis pada bagian time besar di asumsikan sebagai noise, akan dijelaskan pada bagian selanjutnya.

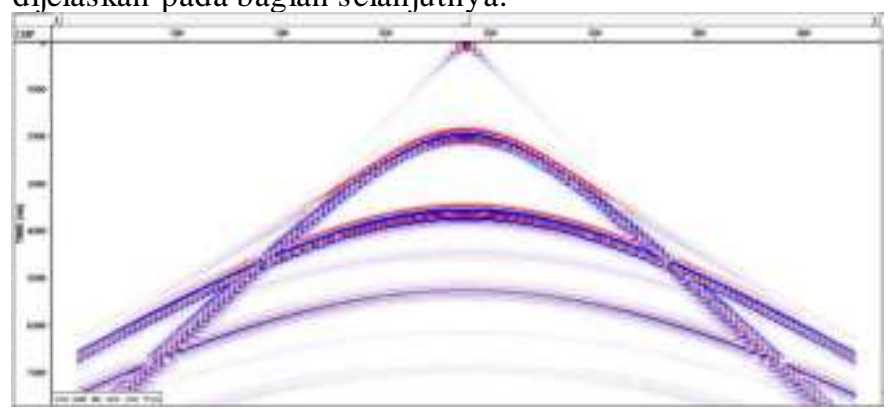

Gambar 2. CMP gather 300 (tengah lintasan dengan fold terbanyak).

\section{Model Geologi Kompleks}

Model Geologi yang digunakan adalah hasil modifikasi dari penampang geologi North Serayu Basin. Model geologi ini digunakan karena memiliki petroleum play mulai dari source rock, reservoir, trap, dan seal.

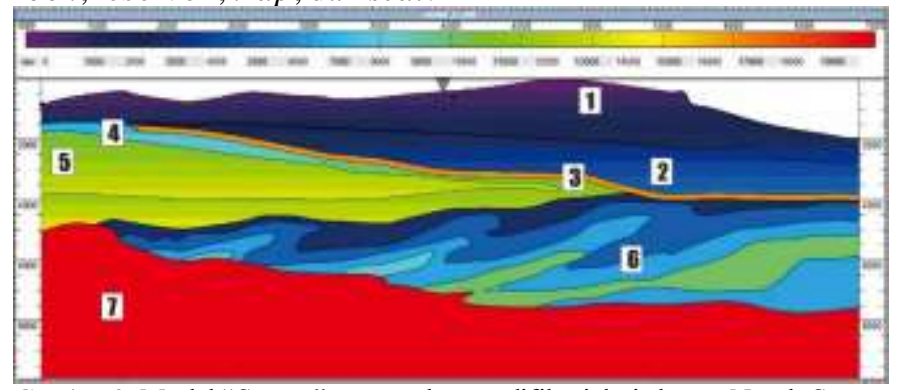

Gambar 3. Model "Serayu”, merupakan modifikasi dari skema North Serayu basin dan telah diberikan properti fisis di setiap lapisan yang didefinisikan. memiliki dimensi panjang $20 \mathrm{Km}$ dengan kedalaman $10 \mathrm{Km}$. Memiliki elevasi berkisar 0 meter hingga 1000 meter (digambar ulang berdasarkan van Bemmelen, 1949; Satyana and Armandita, 2004).

Tabel 3. Properti fisis model Serayu

\begin{tabular}{|c|c|c|c|c|}
\hline $\begin{array}{l}\text { Lapisan } \\
\text { ke }\end{array}$ & Tipe Lapisan & $\begin{array}{l}\mathrm{VP} \\
(\mathrm{m} / \mathrm{s})\end{array}$ & $\begin{array}{l}\text { Densitas } \\
\left(\mathrm{kg} / \mathrm{m}^{3}\right)\end{array}$ & $\begin{array}{l}\text { Ketebalan } \\
(\mathrm{m})\end{array}$ \\
\hline 1 & Soil & $\begin{array}{c}1000- \\
1800\end{array}$ & 1565 & 4000 \\
\hline $\begin{array}{l}2 \\
3\end{array}$ & $\begin{array}{c}\text { Batuan Pasir } \\
\text { Basalt }\end{array}$ & $\begin{array}{l}2000 \\
6000\end{array}$ & $\begin{array}{l}2010 \\
2650\end{array}$ & $\begin{array}{c}1000 \\
200\end{array}$ \\
\hline 4 & Fasies Vulkanik & $\begin{array}{c}3000- \\
5000\end{array}$ & 2200 & 3400 \\
\hline 5 & Fasies Vulkanik & $\begin{array}{c}4000- \\
5000\end{array}$ & 2350 & 2000 \\
\hline 6 & Sandstone & $\begin{array}{c}2000- \\
3000\end{array}$ & 2200 & 3500 \\
\hline
\end{tabular}




\begin{tabular}{lllll}
\hline \hline 7 & $\begin{array}{l}\text { Basemen } \\
\text { Vulkanik }\end{array}$ & 7000 & 2970 & 3000 \\
\hline \hline
\end{tabular}

\section{E. Desain Akuisisi}

Setelah didapatkan model yang akan digunakan kemudian dilakukan desain akuisisi, hal ini dilakukan untuk mendapatkan data yang diinginkan dengan mempertimbangkan berbagai kondisi seperti ketebalan lapisan, kedalaman lapis an target, dsb.

Untuk penentuan desain akuisisi dan parameter akuisisi dilakukan 4 kali test dengan mengubah beberapa parameter sebagai berikut. Tiap test dilakukan 1 kali shot pada tengah model untuk melihat kualitas data, semua test run menggunakan model pada gambar 6 dengan panjang lintasan $20 \mathrm{Km}$.

Tabel 4. Parameter akuisisi tiap Test

\begin{tabular}{ccccc}
\hline \hline & Test Run & Test Run & Test Run & Test Run \\
& 1 & 2 & 3 & 4 \\
\hline Frekuensi & 10 & 15 & 20 & 25 \\
Grid & 501 & 175 & 131 & 105 \\
Total Shot & 40 & 60 & 80 & 100 \\
Shot Interval & 1001 & 661 & 500 & 400 \\
Total Receiver & 20 & 30 & 40 & 50 \\
Receiver Interval & - & 26 menit & 14 menit & 12 menit \\
Durasi 1 kali shot & - & 72 jam & 30,5 jam & 21 jam \\
Estimasi Full & - & & \\
Shot & &
\end{tabular}

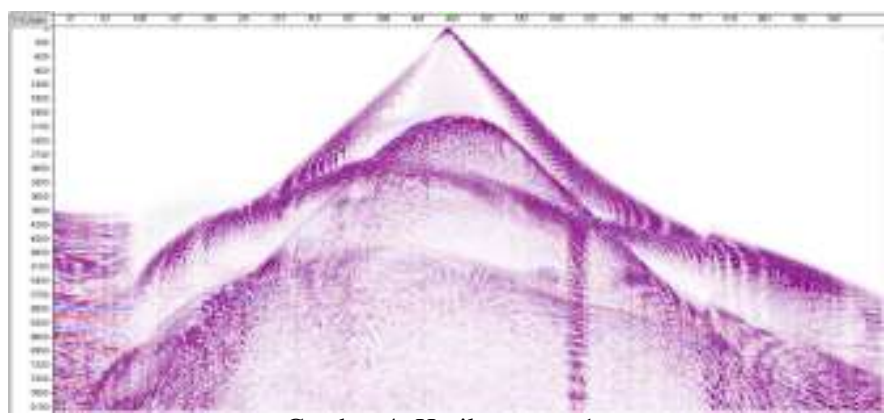

Gambar 4. Hasil test run 1.

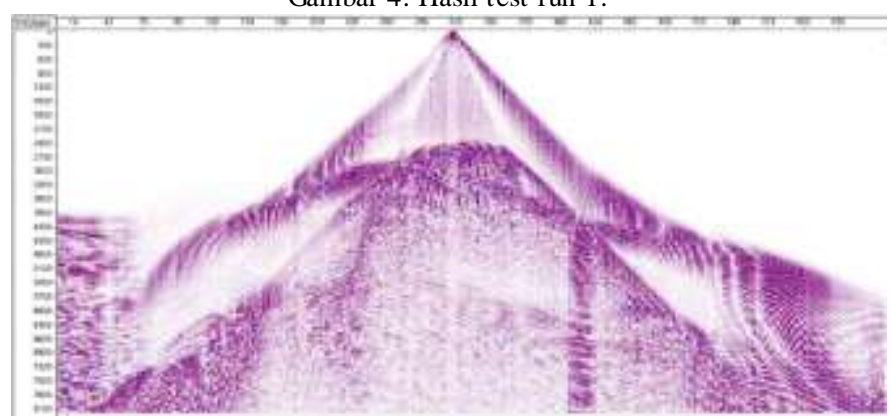

Gambar 5. Hasil test run 2.

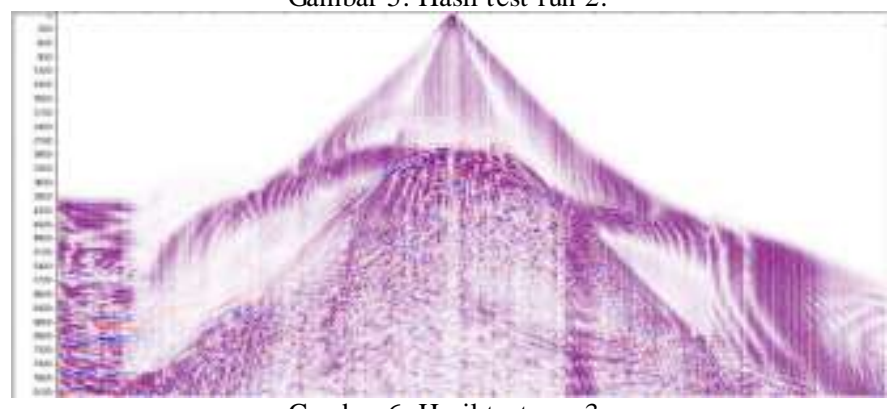

Gambar 6. Hasil test run 3.

Beberapa parameter yang mempengaruhi durasi penghitungan pemodelan atau limitasi kecepatan perhitungan sebagai berikut,
$\Delta \mathrm{d}=\frac{\mathrm{Vp}[\mathrm{min}]}{\mathrm{F}[\mathrm{pick}] / \text { Basewave }}$

Untuk durasi waktu 1 kali komputasi (pemodelan dengan satu sumber)

$\Delta \mathrm{t}=\frac{\Delta \mathrm{d}}{\mathrm{Vp}[\max ] / \text { Stability }}$

Dengan $\mathrm{Vp}[\mathrm{min}]$ adalah nilai Vp minimum, $\mathrm{Vp}[\max ]$ adalah nilai Vp maksimum, F[pick] adalah nilai frekuensi yang diberikan pada sumber, dan stability adalah sqrt (2) + 1/2/Basewave mendekati 1.5 - stability konstan. Sehingga ketika diberikan Vp yang besardan frekuensi yang rendah maka durasi perhitungan akan semakin panjang karena berbanding terbalik.

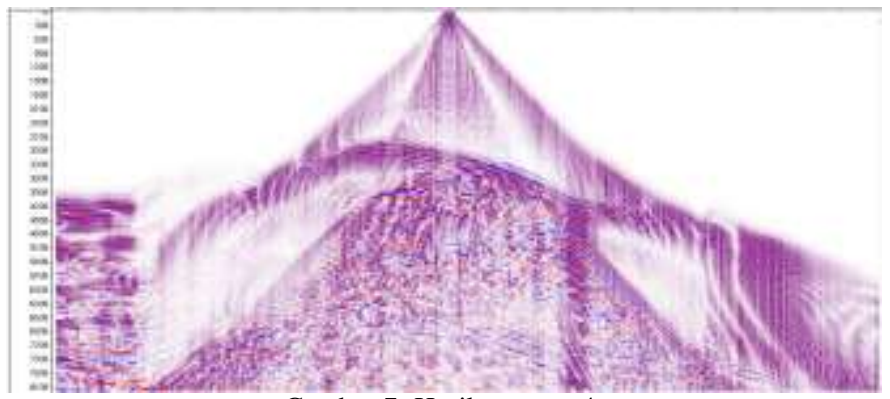

Gambar 7. Hasil test run 4.

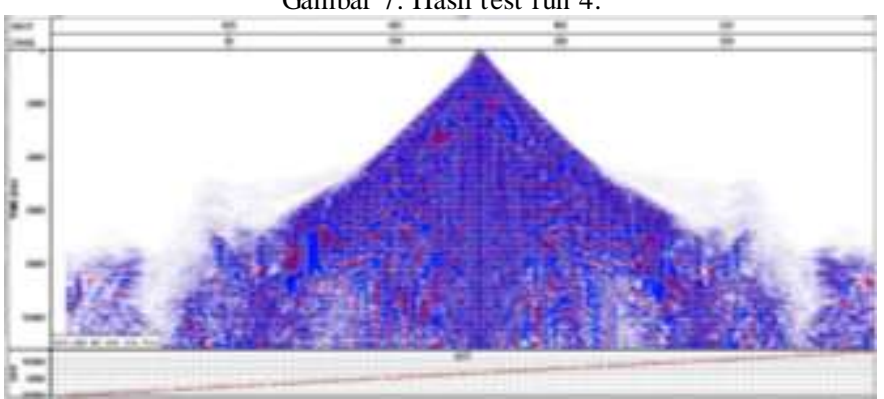

Gambar 8. Seismic Section pada cmp 500 dengan menggunakan frekuensi shot sebesar $30 \mathrm{~Hz}$. Terlihat minimnya even parabolik pada far offset yang dapat menyebabkan minimnya penggambaran pada even refleksi yang dalam.

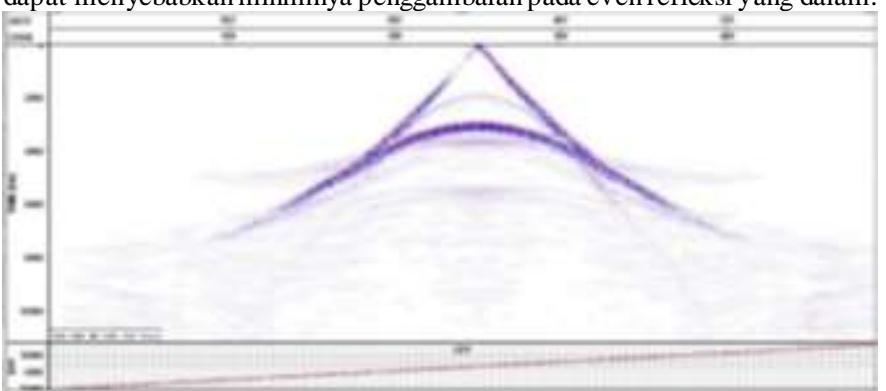

Gambar 9. Seismic Section pada cmp 500 dengan menggunakan frekuensi shot sebesar $5 \mathrm{~Hz}$

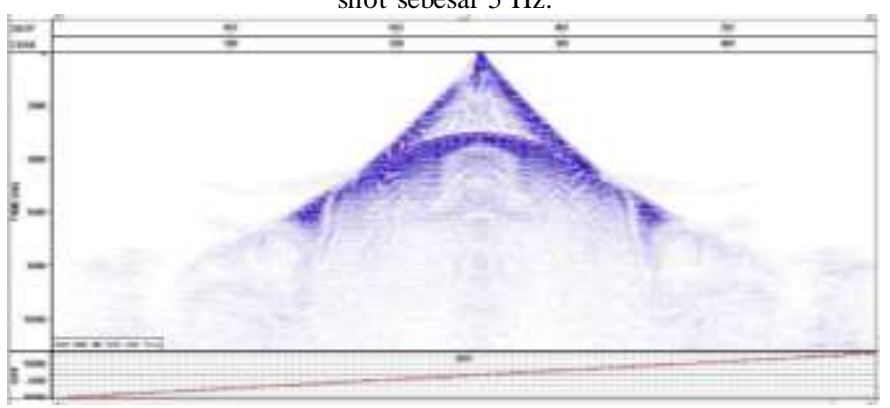

Gambar 10. Seismic Section pada cmp 500 dengan menggunakan frekuensi shot sebesar $10 \mathrm{~Hz}$.

Pemilihan frekuensi shot harus memperhatikan berbagai faktor, jika frekuensi yang diberikan tinggi maka akan 
memberikan energi yang besar yang berakibat amplitudo yang terekam akan besar, hal ini bagus tetapi pemilihan frekuensi yang tinggi memiliki risiko pendeknya panjang gelombang sehingga sulit untuk melakukan penetrasi pada lapisan yang dalam. Sebaliknya, frekuensi rendah memiliki panjang gelombang yang lebih panjang sehingga dapat melakukan penetrasi pada lapisan dalam. Dengan pertimbangan itu dan melihat hasil pemodelan pada Gambar 4.33, 4.34, dan 4.35 maka dipilih frekuensi yang akan digunakan sebesar $5 \mathrm{~Hz}$.

\section{F. KESIMPULAN}

Adapun hal yang dapat disimpulkan daripenelitian iniadalah sebagai berikut:

$>$ Dibutuhkan frekuensi yang sangat kecil $(5 \mathrm{~Hz})$ karena terdapat lapisan basalt dengan ketebalan 200 meter, sehingga gelombang seismik dapat melakukan penetrasi melewati lapisan tersebut.

$>$ Disain akuisisi sangat berpengaruh terhadap kualitas data yang dihasilkan, oleh karena itu dibutuhkan test parameter untuk mengetahui disain akuisisi yang sesuai.

$>$ Pemodelan seismik baik digunakan untuk mendisain survey pada lingkungan vulkanik untuk mengetahui hasil perekaman dan sebagai bahan uji kualitas data bila memiliki informasi geologi pada lapangan survey.

\section{DAFTAR PUSTAKA}

[1] Satyana, A.H., 2015, Subvolcanic Hydrocarbon Prospectivity ofJava: Opportunities and Challenges, Proceedings Indonesian Petroleum Association, 39th Annual Convention and Exhibition, Jakarta, May 2015.

[2] Virieux, J., 1986, Wave Propagation in Heterogeneous Media:Velocitystress Finite Difference Method. Geophysics, 51, 901. 